\title{
Integrative review: what is it? How to do it?
}

\author{
Revisão integrativa: o que é e como fazer \\ Marcela Tavares de Souza ${ }^{1}$, Michelly Dias da Silva ${ }^{2}$, Rachel de Carvalho ${ }^{3}$
}

\begin{abstract}
Introduction: The integrative review is the methodology that provides synthesis of knowledge and applicability of results of significant studies to practice. Objective: To present the phases of an integrative review and the relevant aspects to be taken into account when using this methodological resource. Methods: This study was based on bibliographic search and on the experience of the authors when performing an integrative review. Results: Presentation of the six stages of the integrative review process: preparing the guiding question, searching or sampling the literature, data collection, critical analysis of the studies included, discussion of results and presentation of the integrative review. Conclusions: Considering the need to assure care based on scientific evidence, the integrative review has been identified as a unique tool in healthcare for it synthesizes investigations available on the given topic and guides practice based on scientific knowledge.
\end{abstract}

Keywords: Literature review as topic; Methodology; Nursing methodology research ; Evidence-based nursing

\section{RESUMO}

Introdução: A revisão integrativa é metodologia que proporciona a síntese de conhecimento e a incorporação da aplicabilidade de resultados de estudos significativos na prática. Objetivo: Apresentar as fases constituintes de uma revisão integrativa e os aspectos relevantes a serem considerados para a utilização desse recurso metodológico. Métodos: Trata-se de um estudo realizado por meio de levantamento bibliográfico e baseado na experiência vivenciada pelas autoras por ocasião da realização de uma revisão integrativa. Resultados: Apresentação das seis fases do processo de elaboração da revisão integrativa: elaboração da pergunta norteadora, busca ou amostragem na literatura, coleta de dados, análise crítica dos estudos incluídos, discussão dos resultados e apresentação da revisão integrativa. Conclusões: Diante da necessidade de assegurar uma prática assistencial embasada em evidências científicas, a revisão integrativa tem sido apontada como uma ferramenta ímpar no campo da saúde, pois sintetiza as pesquisas disponíveis sobre determinada temática e direciona a prática fundamentando-se em conhecimento científico.

Descritores: Literatura de revisão como assunto; Metodologia; Pesquisa metodológica em Enfermagem; Enfermagem baseada em evidências

\section{INTRODUCTION}

Due to the increasingly growing amount and complexity of information in the field of health, developing artifacts in scientific research that could lead to more concise methodological stages and offer professionals better use of evidence from several studies became crucial. In this scenario, integrative review is the methodology that provides synthesis of knowledge and applicability of results of significant studies into practice ${ }^{(1)}$.

The method analyzed is basically the tool of Evidencebased Practice (EBP). Originated from the works by the epidemiologist Archie Cochrane, EBP is characterized by an approach of clinical care and teaching based on knowledge about evidence and its quality. Therefore, it involves defining the clinical problem, identifying the necessary information, searching studies in the literature and evaluating them critically, identifying applicability of data from publications, and determining their use to patients $^{(2)}$.

The EBP initiatives have increased the need for producing all types of literature review. Although important, the review methods most often used - systematic review and meta-analysis - do not contemplate relevant nursing issues related to care and/or impact of disease or of treatment. Due to its methodological approach, the integrative review allows including diverse methods, which can potentially play the significant role in EBP in Nursing ${ }^{(3)}$. Hence, it is

\footnotetext{
'Nurse; Specialist in Clinical and Surgical Nursing of the Faculdade de Enfermagem of Hospital Israelita Albert Einstein - FEHIAE, São Paulo (SP), Brazil.

${ }^{2}$ Nurse; Specialist in Clinical and Surgical Nursing of the Faculdade de Enfermagem of Hospital Israelita Albert Einstein - FEHIAE, São Paulo (SP), Brazil.

${ }^{3} \mathrm{PhD}$ in Nursing; Lecturer and Coordinator of Graduate Courses of the Faculdade de Enfermagem of Hospital Israelita Albert Einstein - FEHIAE, São Paulo (SP), Brazil.

Corresponding author: Marcela Tavares de Souza - Rua Ayrton Perón, 465 - Jardim dos Ipês - CEP 79600-000 - Três Lagoas (MS), Brasil - e-mail: mtavares51@gmail.com

Received on Dec 12, 2008 - Accepted on June 8, 2009

The authors declare no conflict of interest.
} 
fundamental to differentiate it from other existing lines of studies.

Meta-analysis is the review method that combines evidence of multiple primary studies by using statistical tools to enhance objectivity and validity of the findings. The design and hypotheses of the studies should be very similar, if not identical. In the meta-analysis approach, each study is synthesized, codified and input in quantitative database. Subsequently, the results are transformed into a common measure to calculate the general dimension of the effect or of the intervention considered $^{(3)}$.

Systematic review, in turn, is an exacting synthesis of all investigations related to one specific question, focusing primarily on experimental studies, such as randomized clinical trials. It is different from other methods of review since it aims at overcoming possible biases in each stage, following a strict method to search and select investigations; assessing relevance and validity of the studies found; collection, synthesis and interpretation of data from research ${ }^{(2)}$.

Lastly, integrative review is the most comprehensive methodological approach of reviews, and it allows including experimental and non-experimental studies to fully understand the phenomenon analyzed. It also combines data from theoretical and empirical literature, and has a wide range of purposes, such as definition of concepts, review of theories and evidence, and analysis of methodological problems of a particular topic. The broad sample, together with multiple proposals, should create a consistent and comprehensive panorama of complex concepts, health theories or problems that are relevant for nursing ${ }^{(3)}$.

\section{OBJECTIVE}

Considering this information and aiming to provide subsidies for construction and/or application of integrative reviews in the field of nursing, the purpose of this article is to present the phases of an integrative review and the relevant aspects to be taken into account when using this important methodological resource.

\section{METHODS}

It is a study with data collected from secondary sources through a bibliographic search and based on the experience of the authors when performing an integrative review.

Bibliographical survey is one of the best ways to initiate a study, searching for similarities and differences among the articles found in the references. The electronic compilation of information is a major advance for researchers for it democratizes access and provide frequent update ${ }^{(4)}$. The general objective of a literature review is to gather knowledge about a topic, thus assisting to set the foundations for a significant study on nursing. This task is crucial for researchers $^{(5)}$.

To survey articles in the literature, the following databases were used: Latin-American and Caribbean Health Sciences Literature (LILACS) and Medical Literature Analysis and Retrieval System on-line (Medline).

The descriptors, and their combinations in Portuguese and English, employed to search articles were as follows: "Methodology", "Method", "Literature review as subject", "Research in nursing" and "Evidencebased Medicine".

The inclusion criteria defined to select articles were: articles published in Portuguese, English and Spanish; full articles addressing integrative review and articles published and indexed in the above-mentioned databases in the last ten years.

The analysis of the studies selected in terms of research design was based on Polit, Beck, Hungler ${ }^{(5)}$ and Lo Biondo-Wood, Haber ${ }^{(6)}$. Both analysis and synthesis of data extracted from the articles were carried out in a descriptive fashion, allowing to observe, count, describe and classify data in order to gather knowledge produced on the topic addressed in this review.

\section{RESULTS}

The final sample of this review comprised five scientific articles, selected according to the inclusion criteria previously established. One article was found in the database LILACS and four in the Medline. The chart 1 represents the specifications of each article.

Hence, scarcity of published scientific articles on integrative review was observed, since it is a methodology derived from Evidence-based Practice, which is increasingly developing in nursing, as well as in all other areas in the field of health.

Within this context, the concept and the phases of an integrative review are addressed as an EBP tool.

\section{DISCUSSION}

Integrative review determines current knowledge about a specific topic because it is carried out to identify, analyze and synthesize results of independent studies on the same subject, thus contributing to a possible beneficial repercussion on quality of care delivered to patients $^{(1)}$. It is noteworthy mentioning that the use of integrative review impacts not only in development of policies, protocols and procedures, but also in critical assessment that the daily practice demands ${ }^{(7)}$. 
Chart 1. Articles surveyed in the databases LILACS and MEDLINE on integrative review.

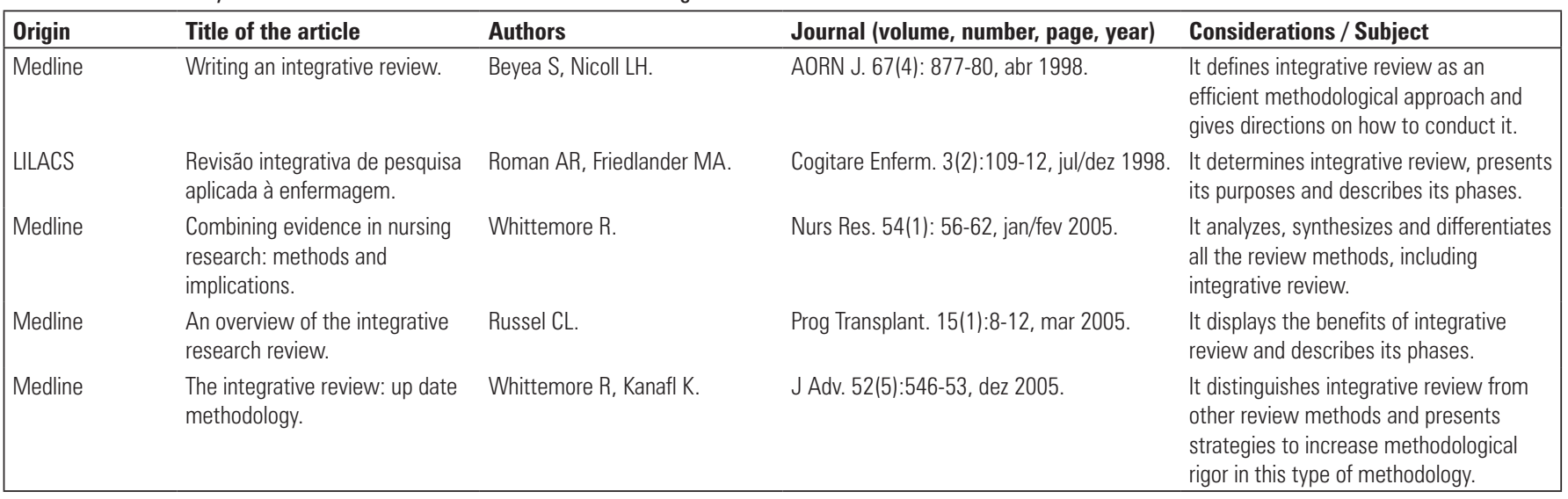

Next, the six phases of the process of preparing an integrative review are briefly presented ${ }^{(8)}$.

\section{$\mathbf{1}^{\text {st }}$ phase: preparing the guiding question}

Defining the guiding question is the most important phase of the review, because it determines which studies will be included, the means adopted for identification and information gathered in each selected study. Hence, it includes the definition of participants, the interventions to be evaluated and the results to be measured ${ }^{(2)}$. It should be clearly and specifically prepared, and related to a theoretical principle that comprises theories and rationale learned by the researcher ${ }^{(1,9)}$.

\section{$2^{\text {nd }}$ phase: searching or sampling the literature}

Intrinsically related to the previous phase, the search in databases should be broad and diverse, including search in electronic databases, manual search in journals, the references described in the selected studies, contact with researchers and the use of unpublished material ${ }^{(2)}$. The sampling criteria must assure representativeness of the sample, and they are important indicators of reliability and veracity of the results. The ideal procedure is to include all the studies found or a randomized selection of them; however, if both choices are not feasible due to the amount of works, the inclusion and exclusion criteria adopted for the articles must be clearly explained and discussed $^{(8)}$. Thus, determining the criteria should be performed in agreement with the guiding question, considering the participants, the intervention and the results of interest.

\section{$3^{\text {rd }}$ phase: data collection}

To extract data from the articles selected, it is necessary to use a previously prepared instrument that is able to assure collection of all relevant data, to minimize the risk of errors in transcription, to guarantee precision when checking information and to serve as a record. The data should include definition of the subjects, methodology, size of the sample, measuring variables, method of analysis and concepts used as bases is the Appendix 1 is a model of an instrument to be used in data collection ${ }^{(8,9)}$.

\section{$4^{\text {th }}$ phase: critical analysis of the studies included}

Similar to data analysis in conventional research, this phase demands an organized approach to weigh rigor and characteristics of each study. The clinical experience of the researcher contributes to check validity of the methods and results, and helps determining their usefulness in practice ${ }^{(1,9)}$.

Differently, the Evidence-based Practice (EBP) focus on evidence classification systems, which are hierarchically characterized depending on the methodological approach adopted. To assist in choosing the best possible evidence, a hierarchy of evidence is proposed, based on the design of the research, which is one of the items to be analyzed in this phase ${ }^{(7)}$.

- Level 1: evidence resulting from meta-analysis of multiple randomized controlled clinical trials;

- Level 2: evidence from individual studies with experimental design;

- Level 3: evidence from quasi-experimental studies;

- Level 4: evidence of descriptive (non-experimental) studies or with a qualitative approach;

- Level 5: evidence from case reports or from experience;

- Level 6: evidence based on opinions of specialists.

\section{$\mathbf{5}^{\text {th }}$ phase: discussion of results}

In this stage, based on interpretation and synthesis of results, the data demonstrated in the analysis of the 
articles are compared to the theoretical reference. In addition to identifying eventual gaps in knowledge, it is possible to set priorities for future studies. Nonetheless, to protect validity of the integrative review, the investigators must stress their conclusions and inferences, and also explain the biases ${ }^{(9)}$.

\section{$6^{\text {th }}$ phase: presentation of the integrative review}

The presentation of the review must be clear and complete to enable the reader to critically assess the results. It should contain relevant and detailed pieces of information based on contextualized methodologies, without omission of any related evidence ${ }^{(1,9)}$.

In integrative review, the combination of several methodologies may contribute to lack of rigor, inaccuracy and bias; thus, it should be conducted within the methodological rigor standards ${ }^{(3)}$. It is therefore imperative to make punctual considerations about some phases of the process, namely collection, analysis and discussion of data.

One of the methods to analyze data of a qualitative research concerns variety of findings of integrative review $^{(3)}$. It consists of reduction, presentation and comparison of data, as well as conclusion and verification of data.

Reducing data involves determining the general classification system to manage diverse methodologies. First, the studies should be divided into subgroups according to a previously established classification, aiming to facilitate the analysis. In integrative reviews, for instance, the categorization may be based on the type of incidence, chronology or characteristics of the sample, or on some predetermined conceptual classification.

Next, data are extracted from the primary sources using the prepared instrument to simplify, summarize and organize the findings, so that each study is reduced to one page with relevant content (Appendix 1). Such approach, in addition to enabling a brief organization of data, facilitates comparison among studies in specific topics, such as problems, variables and characteristics of the sample.

The following step is the visualization of data, that is, converting the findings into a visual form of subgroups. The visualization modes may be depicted in tables, graphs or charts, in which all selected studies can be compared. Moreover, identification of patterns, differences and redistribution of these topics may be included as part of the general discussion.

Any statements regarding relations or conclusions demand verifying the primary source to avoid premature conclusions or exclusion of relevant evidence during the process.

\section{CONCLUSIONS}

Considering the need to assure care based on scientific evidence, the integrative review has been identified as a unique tool in healthcare for synthesizing investigations available on the given topic and for directing practice based on scientific knowledge. Although combining data of investigations with diverse design is quite complex and challenging, performing integrative review, based on inclusion of a systematic and rigorous approach of the process, particularly data analysis, results in reduced biases and errors. For this reason, it is imperative to establish integrative review as a valid instrument of Evidence-based Practice, primarily in the current scenario of Brazilian nursing.

\section{REFERENCES}

1. Silveira RCCP. 0 cuidado de enfermagem e o cateter de Hickman: a busca de evidências [dissertation]. Ribeirão Preto: Universidade de São Paulo, Escola de Enfermagem de Ribeirão Preto; 2005.

2. Galvão CM, Sawada NO, Trevizan MA. Revisão sistemática: recurso que proporciona a incorporação das evidências na prática da enfermagem. Rev Latino-Am Enfermagem. 2004;12(3):549-56.

3. Whittemore R, Knafl K. The integrative review: update methodology. J Adv Nurs. 2005;52(5):546-53.

4. Brevidelli MM, De Domenico EB. Trabalho de conclusão de curso: guia prático para docentes e alunos da área da saúde. 2a ed. São Paulo: látria; 2008.

5. Polit DF, Beck CT, Hungler BP. Fundamentos de pesquisa em enfermagem: métodos, avaliação e utilização. 5a ed. Porto Alegre (RS): Artmed, 2004.

6. Lo Biondo-Wood G, Haber J. Pesquisa em enfermagem: métodos, avaliação crítica e utilização. 4a ed. Rio de Janeiro: Guanabara Koogan; 2001.

7. Stetler CB, Morsi D, Rucki S, Broughton S, Corrigan B, Fitzgerald J, et al. Utilization-focused integrative reviews in a nursing service. Appl Nurs Res. 1998;11(4):195-206.

8. Ganong LH. Integrative reviews of nursing research. Res Nurs Health. 1987;10(1):1-11.

9. Ursi ES. Prevenção de lesões de pele no perioperatório: revisão integrativa da literatura. [dissertation]. Ribeirão Preto: Universidade de São Paulo, Escola de Enfermagem de Ribeirão Preto; 2005. 
APPENDIX 1. Example of a data collection instrument (validated by Ursi, 2005).

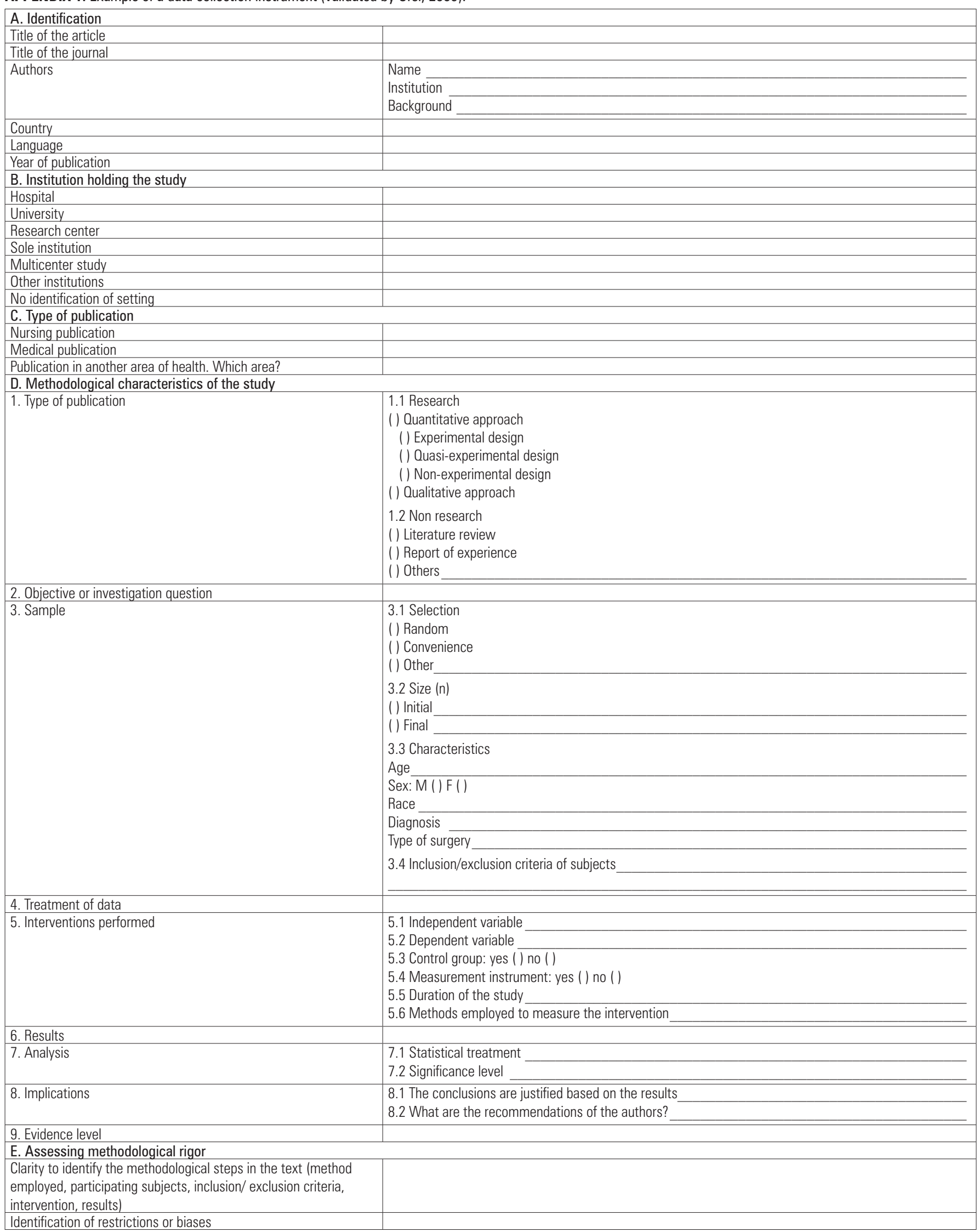

